\section{- OPEN ACCESS}

\title{
Lemierre's syndrome: forgotten, but not absent
}

\author{
Mandreker Bahall, ${ }^{1}$ Stanley Giddings, ${ }^{1}$ Krishni Bahall ${ }^{2}$
}

'Department of Clinical and Medical Sciences, University of the West Indies., St. Augustine, Trinidad and Tobago

${ }^{2}$ Department of Medicine, San Fernando General Hospital, San Fernando., Trinidad and Tobago

\section{Correspondence to} Dr Mandreker Bahall, vmandrakes@hotmail.com

Accepted 20 July 2017

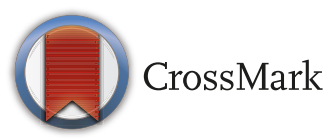

To cite: Bahall $\mathrm{M}$, Giddings S, Bahall K. BMJ Case Rep Published Online First: [please include Day Month Year]. doi:10.1136/ bcr-2017-221203

\section{SUMMARY}

Lemierre's syndrome is rare, with no known reported cases in the Caribbean thus far. We highlight a case of a young woman who presented with diabetic ketoacidosis precipitated by oral pharyngeal sepsis, whose condition rapidly deteriorated within 24 hours requiring ventilation and administration of antibiotics. Her sepsis was accompanied by internal jugular vein thrombosis in keeping with a diagnosis of Lemierre's syndrome, which was treated aggressively with antibiotics, intensive care and mechanical ventilatory support in the intensive care unit. She made a full recovery. Though this is the first reported case in the Caribbean of this 'forgotten disease', it must not be forgotten because prognosis and outcome are markedly improved with prompt and aggressive treatment.

\section{BACKGROUND}

Lemierre's syndrome as a complication of oropharyngeal sepsis has rarely been diagnosed and has never been reported in West Indian literature. It was first described by Courmont and Cade in 1900, but was finally named by Dr Andre Lemierre, a French microbiologist, in $1936 .{ }^{1}$ Lemierre's syndrome is characterised by bacteraemia following a recent oropharyngeal infection and thrombophlebitis of the internal jugular vein. ${ }^{2}$ It is more common in men, ${ }^{3}$ and generally occurs in the second decade of life. ${ }^{4}$ Its approximate incidence is 0.8 per million persons per year ${ }^{5}$ and mortality, compared with the preantibiotic era, is much improved at $0 \%-18 \% .^{6-8}$ Although it is viewed as a "forgotten disease" 10 it must be explored as a differential diagnosis for oropharyngeal sepsis. Lemierre's syndrome can be life threatening if it is not promptly recognised and treated adequately. Bacteraemia in Lemierre's can be polymicrobial, ${ }^{11}$ with Fusobacterium necrophorum reported in $90 \%$ of the cases. ${ }^{12}$ Septic thrombophlebitis of the jugular vein, one of the key characteristics of this syndrome, leads to thrombosis and septic emboli via haematological spread to other organs. ${ }^{613}$ We describe a case of a previously healthy young woman who presented with diabetic ketoacidosis precipitated by an infection. She rapidly deteriorated within 24 hours, requiring ventilation and intravenous administration of antibiotics. She made a complete recovery and was discharged after 20 days.

\section{CASE PRESENTATION}

A 25-year-old woman with diabetes presented to the emergency department with a 1-week history of headache, right-side neck and shoulder pain and a 2-day history of intermittent fever, dry cough and odynophagia. Examination revealed a young woman, oriented in time, place and person. She was ill looking, afebrile (temperature $37^{\circ} \mathrm{C}$ ), with a pulse of $115 \mathrm{bpm}$ and blood pressure of $95 / 60 \mathrm{~mm} \mathrm{Hg}$. Respiratory, cardiovascular, neurological and abdominal examinations were normal. Kernig's and Brudzinski's signs were negative. She had right-side neck tenderness and exudative tonsillitis.

\section{INVESTIGATIONS}

Investigations revealed a white blood cell (WBC) count of $7.7\left(4.1-11.2 \times 10^{3} / \mathrm{uL}\right)$, haemoglobin of $10.9(11.7-15.5 \mathrm{~g} / \mathrm{dL})$, thrombocytopaenia with a platelet count of $22\left(159-399 \times 10^{3} / \mathrm{uL}\right)$ and elevated C reactive protein level of $33.9(0-0.5 \mathrm{mg} /$ dL). She had toxic granulation on blood film. Initial electrolytes, blood urea nitrogen (BUN) and creatinine levels were normal: $\mathrm{Na} 136$ (138$146 \mathrm{mmol} / \mathrm{L}), \mathrm{K} 4.6(3.5-5.0 \mathrm{mmol} / \mathrm{L})$, BUN 14 $(8-26 \mathrm{mg} / \mathrm{dL})$ and creatinine $0.4(0.6-0.9 \mathrm{mg} / \mathrm{dL})$. Liver function tests were within normal ranges: aspartate aminotransferase (AST) 27 (16-40 IU/L) and alanine aminotransferase (ALT) 3 (10-55 IU/L), with a mild direct hyperbilirubinaemia: direct bilirubin $2.0(0.1-0.4 \mathrm{mg} / \mathrm{dL})$ and total bilirubin 2.4 $(0.4-1.4 \mathrm{mg} / \mathrm{dL})$. An ECG showed a sinus tachycardia and chest X-ray showed bilateral infiltrates without pleural effusions. However, a right pleural effusion was noted on a repeat chest X-ray 2 days later. CT imaging of the neck and chest revealed acute thrombosis of the right internal jugular vein and septic emboli throughout the lung parenchyma bilaterally. Duplex of the right upper limb and neck showed thrombosis of the right internal jugular vein. The prothrombin, partial thromboplastin and international normalised ratio were: $12.7 \mathrm{~s}, 35.6 \mathrm{~s}$ and 1.18 (normal range: 9.5-13.5, 27.0-35.0, 0.8-1.2), respectively. HIV, Monospot and Mantoux tests were all negative. Immunology screening revealed an antinuclear antibody $1+$ finespeckled pattern and anti-DNA negative. An extractable nuclear antigen panel showed $\mathrm{MI2A++,} \mathrm{RP11+,} \mathrm{and} \mathrm{RP155+.} \mathrm{Complement}$ levels (C3 and $\mathrm{C} 4$ ) were within normal ranges at $157 \mathrm{mg} / \mathrm{dL}(90-180)$ and $26 \mathrm{mg} / \mathrm{dL}(10-40)$, respectively, and she was negative for cytoplasmic antineutrophil cytoplasmic antibodies. An echocardiogram was normal with no vegetation or thrombus. Urine and blood cultures both revealed no bacterial growth after 5 days. Antiphospholipid and thrombophilia screening, erythrocyte sedimentation rate and perinuclear antineutrophil cytoplasmic antibodies were unavailable. 


\section{TREATMENT}

Following basic investigations, the patient commenced ceftriaxone treatment. On day 2 post hospitalisation, she became markedly distressed, acidotic ( $\mathrm{pH} 7.159$ ) and was transferred to the intensive care unit for ventilatory support and continuation of meropenem and vancomycin antibiotics as well as vasopressors. She was also anticoagulated with rivaroxaban for the treatment of the internal jugular vein thrombosis.

\section{OUTCOME AND FOLLOW-UP}

Acute kidney injury developed within 2 days with a rise in creatinine to $1.9 \mathrm{mg} / \mathrm{dL}$. This resolved during the course of treatment.

Her course was otherwise unremarkable and uneventful, with full recovery. She was discharged on day 20 with oral anticoagulants, oral antibiotics and insulin therapy with scheduled follow-up at the outpatient medical and diabetes clinics.

\section{DISCUSSION}

We highlight a very common presentation of acute tonsillitis that was complicated by thrombophlebitis, internal jugular vein thrombosis and multiple septic emboli to the lungs known as Lemierre's syndrome. Our patient presented with neck pain, fever, dry cough and odynophagia. Similar symptoms were noted in other studies. The frequencies of common features included a sore throat (82.5\%), which usually preceded all other symptoms; fever (82.5\%-100\%); swollen and/or tender neck (52.2\%); jaundice (33\%) with deranged liver enzymes and hyperbilirubinaemia. ${ }^{7}$ As found in this case, many patients demonstrate classical symptoms in keeping with less sinister conditions such as acute viral pharyngitis. ${ }^{14} \mathrm{~A}$ high index of suspicion is therefore needed as the diagnosis is mainly a clinical one. ${ }^{15}$ A bacterial pathogen may be identified from blood cultures. It is not surprising to obtain a negative blood culture as was found in our case, as many studies also failed to identify a causative organism. ${ }^{16}$ The absence of positive blood cultures should not negate this clinical diagnosis as antibiotics may have commenced before taking blood cultures. Furthermore, it is not a major criterion for Lemierre's, as cultures are often negative. ${ }^{17}$ It is also important to note that F. necrophorum, the most commonly identified organism, may take up to 7 days to grow in blood culture and may be mistaken for Bacteroides sp. ${ }^{610} \mathrm{~F}$. necrophorum are gram-negative bacilli, obligate anaerobes whose existence in normal oral flora is debatable. ${ }^{18}$ Infection is precipitated by mucosal damage that facilitates entry and extension into the parapharyngeal spaces and is further propagated by the organism's multiple virulence factors. Lemierre's syndrome was also known as postanginal sepsis due to its association with disease of the nasopharyn $\mathrm{x}^{3}$ and necrobacillosis as a result of the necrotic abscesses produced by F. necrophorum. ${ }^{19}$ Other pathogens such as Bacteroides sp, Prevotella, Peptostreptococcus, Eikenella corrodens and Streptococcus among others have been identified. ${ }^{8}$ Severe thrombocytopaenia without bleeding is consistent with F. necrophorum subspecies necrophorum, the only organism that aggregates platelets. ${ }^{6}$ Both severe thrombocytopaenia and the presence of necrotic abscesses support $F$. necrophorum as the aetiological agent even though the cultures were negative. CT scans at presentation revealed thrombosis of the internal jugular vein, which is found in $30 \%-70 \%$ of cases, ${ }^{20}$ and septic emboli to the lungs, which is the most common site for metastatic septic foci. ${ }^{7}$

The diagnosis of classical Lemierre's syndrome is based on fulfilling three criteria; namely, oropharyngeal sepsis, internal jugular vein thrombophlebitis and metastatic infection, ${ }^{21}$ as was
Learning points

- Lemierre's syndrome is rare

- It may be a re-emerging disease.

- Its rather mundane presentation demands that healthcare providers be vigilant for Lemierre's syndrome.

found in our case. Differential diagnoses besides viral pharyngitis include pneumonia, infective endocarditis, acute retroviral illness, infectious mononucleosis and leptospirosis. ${ }^{14}$

Treatment was initiated with ceftriaxone, which was subsequently switched to meropenem and vancomycin 24 hours after admission when our patient developed acute respiratory distress and required ventilation. According to various authors as cited by Lu et $a l,{ }^{13}$ and Riordan et al, ${ }^{6}$ antibiotics directed at anaerobes are most effective, especially clindamycin, cefoxitin, imipenem and combination therapy with metronidazole and penicillin. The microbes are generally resistant to macrolides and even more so to gentamicin and quinolones. The development of acute respiratory distress syndrome is rare. ${ }^{14}$ However, our case demonstrated a marked improvement after just 5 days in the intensive care unit, after which she was managed in the medical ward where she was anticoagulated for internal jugular vein thrombosis. Anticoagulation therapy in Lemierre's is controversial. ${ }^{6}$ Studies have suggested the potential for haematogenous spread of infection with this therapy. ${ }^{17}$ Features supporting anticoagulation initiation in a case series by Lu et $a l^{13}$ include the retrograde extension of the thrombus to involve the cavernous sinus, failure to improve after adequate antimicrobial therapy for 2-3 days or coexisting thrombophilia. This case had neither of the first two indications. However, in light of the unavailability of antiphospholipid antibody testing and thrombophilia screening, she was started on oral anticoagulation and will continue receiving this treatment for at least 3 months, as recommended. ${ }^{20}$ Surgical management in the form of ligation or resection of the internal jugular vein is rarely indicated. This may follow in the case of persistent septic embolisation despite appropriate medical therapy. ${ }^{7}$ The acute renal failure in this patient resolved with fluids and antibiotics. Such complications of this syndrome are relatively uncommon and, according to Eykyn and Leugers as cited by Riordan et $a l,{ }^{6}$ fewer than $5 \%$ of cases require renal replacement therapy. Other complications of Lemierre's syndrome include bone and joint manifestations in the form of septic arthritis (13\%-27\%), osteomyelitis (<3\%), skin and soft tissue lesions (0\%-16\%), purulent meningitis (rare in classical Lemierre's) and though unusual, cardiovascular complications such as endocarditis and pericarditis. ${ }^{6}$

Although rare, Lemierre's syndrome is still present. Its rather mundane presentation demands healthcare providers be vigilant for Lemierre's, a not-to-be-forgotten and re-emerging disease. $^{22}$

Contributors MB assisted in the planning, data acquisition, analysis and interpretation, management of case,writing and editing of manuscript. SG assisted in the management of case, data analysis and interpretation and editing of manuscript. $\mathrm{KB}$ assisted in data acquisition, analysis and interpretation, management of case and writing of manuscript.

Competing interests None declared.

Patient consent Obtained.

Provenance and peer review Not commissioned; externally peer reviewed.

Open Access This is an Open Access article distributed in accordance with the Creative Commons Attribution Non Commercial (CC BY-NC 4.0) license, which permits others to distribute, remix, adapt, build upon this work non-commercially, 
and license their derivative works on different terms, provided the original work is properly cited and the use is non-commercial. See: http://creativecommons.org/ licenses/by-nc/4.0/

(c) BMJ Publishing Group Ltd (unless otherwise stated in the text of the article) 2017. All rights reserved. No commercial use is permitted unless otherwise expressly granted.

\section{REFERENCES}

1 Camelo C, Brandao M, Fernandes L, et al. Lemierre syndrome: a case report. J VasC Bras 2015; 14:253-7.

2 Lemierre A. On certain septicemias due to anaerobic organisms. Lancet 1936;1:701-3.

3 Hagelskjaer Kristensen L, Prag J. Human necrobacillosis, with emphasis on Lemierre's syndrome. Clin Infect Dis 2000;31:524-32.

4 Karkos PD, Asrani S, Karkos CD, et al. Lemierre's syndrome: a systematic review. Laryngoscope 2009;119:1552-9.

5 Hagelskjaer LH, Prag J, Malczynski J, et al. Incidence and clinical epidemiology of necrobacillosis, including Lemierre's syndrome, in Denmark 1990-1995. Eur J Clin Microbiol Infect Dis 1998;17:561-5.

6 Riordan T, Wilson M. Lemierre's syndrome: more than a historical curiosa. Postgrad Med J 2004;80:328-34.

7 Chirinos JA, Lichtstein DM, Garcia J, et al. The evolution of Lemierre syndrome: report of 2 cases and review of the literature. Medicine 2002;81:458-65.

8 Riordan T. Human infection with Fusobacterium necrophorum (Necrobacillosis), with a focus on Lemierre's syndrome. Clin Microbiol Rev 2007;20:622-59.

9 Gupta S, Merchant S. Lemierre's syndrome: rare, but life threatening - a case report with. Case Rep Med 2012.
10 Moore-Gillon J, Lee TH, Eykyn SJ, et al. Necrobacillosis: a forgotten disease. BMJ 1984:288:1526-7.

11 Moore BA, Dekle C, Werkhaven J. Bilateral Lemierre's syndrome: a case report and literature review. Ear Nose Throat J 2002:81:234-52.

12 Li HY, Grubb M, Panda M, et al. A sore throat: potentially life-threatening? J Gen Intern Med 2009:24:872-5.

13 Lu MD, Vasavada Z, Tanner C. Lemierre syndrome following oropharyngeal infection: a case series. J Am Board Fam Med 2009;22:79-83.

14 Kushawaha A, Popalzai M, El-Charabaty E, et al. Lemierre's syndrome, reemergence of a forgotten disease: a case report. Cases J 2009;2:6397.

15 Aggarwal SK, Nath A, Singh R, et al. Lemierre's Syndrome presenting with neurological and pulmonary symptoms: case report and review of the literature. Ann Indian Acad Neurol 2013;16:259-63.

16 Johannesen KM, Bodtger U. Lemierre's syndrome: current perspectives on diagnosis and management. Infect Drug Resist 2016:9:221-7.

17 Sudarshana Murthy KA, Thippeswamy T, Kiran HS, et al. Case report: the 'forgotten disease' (or the never known). JAPI 2013;61:754-7.

18 Brazier JS. Human infections with Fusobacterium necrophorum. Anaerobe 2006:12:165-72.

19 Alston JM. Necrobacillosis in Great Britain. Br Med J 1955;2:1524-8.

20 Arora T, Wright D. Lemierre's syndrome in an adult: A case review. Otolaryngology 2014;4:167.

21 Sinave CP, Hardy GJ, Fardy PW. The Lemierre syndrome: suppurative thrombophlebitis of the internal jugular vein secondary to oropharyngeal infection. Medicine 1989:68:85-94.

22 Adeoye SP, Abraham S, Erlikh I, et al. Lemierre syndrome complicating pharyngotonsilitis in a young male: a case report. J Med Cases 2013:4:705-9.

Copyright 2017 BMJ Publishing Group. All rights reserved. For permission to reuse any of this content visit http://group.bmj.com/group/rights-licensing/permissions.

BMJ Case Report Fellows may re-use this article for personal use and teaching without any further permission.

Become a Fellow of BMJ Case Reports today and you can:

- Submit as many cases as you like

- Enjoy fast sympathetic peer review and rapid publication of accepted articles

- Access all the published articles

Re-use any of the published material for personal use and teaching without further permission

For information on Institutional Fellowships contact consortiasales@bmjgroup.com

Visit casereports.bmj.com for more articles like this and to become a Fellow 